\title{
Estrutura Produtiva e Comércio Exterior no Brasil: uma Investigação sobre as Basticidades Renda da Demanda por Exportações e Importações Setoriais ${ }^{*}$
}

\author{
Nelson Marconi ${ }^{\dagger}$ \\ Biane Araujo
}

\begin{abstract}
Resumo
Este trabalho estima as elasticidades-renda da demanda por exportações e importações nos diferentes setores da indústria de transformação brasileira. Para tanto, o trabal ho apresenta alguns aspectos teóricos dos modelos de crescimento com restrição de balanço de pagamentos, discute a abordagem estruturalista associada às características setoriais que influenciam o processo de desenvolvimento econômico e estima e analisa as elasticidadesrenda da demanda para os setores exportadores e importadores da indústria de transformação, individualmente e agregados por intensidade tecnológica. As conclusões da pesquisa são as de que a elasticidade-renda da demanda dos produtos exportados pela indústria intensiva em engenharia, ciência e conhecimento é maior que as elasticidades dos demais ramos da indústria de transformação. O mesmo ocorre em relação às importações. Esse resultado sugere, à luz das teorias estruturalista e de crescimento $\infty m$ restrição de balanço de pagamentos, que uma pauta de exportações concentrada em produtos com maior conteúdo tecnológico pode implicar taxas de crescimento mais elevadas que uma pauta na qual predominam commodities, como é o caso no Brasil.
\end{abstract}

Palavras chaves: Easticidade-Renda, Exportações Setoriais, Mudança Estrutural

\begin{abstract}
This paper estimates the income elasticities of demand for exports and imports in different sectors of the Brazilian manufacturing industry. To do this, this paper presents some theoretical aspects of growth models with balance of payments constraint, discusses the structuralist approach associated with the sectoral characteristics that influence the process of economic development, and estimates and analyzes the income elasticities of demand for the export and import sectors of the manufacturing industry, individually and aggregated by technological intensity. The research findings are that income elasticity of demand for products exported by industry intensity in engineering, science and knowledge is greater than the elasticities of other branches of the manufacturing industry. The same was found for imports. This result suggests, in light of the structuralist theories and the growth with balance of payments constraint, that a basket of exports concentrated in products with higher technological content may imply higher growth than a basket dominated by commodities, as is the case in Brazil.
\end{abstract}

Keywords: Income Easticities, Sector Exports, Structural Changes

HClassification: E10, F43, O19

\footnotetext{
"Uma versão deste artigo foi publicada no livro: Barbosa, N.; Marconi, N.; Pnheiro, M. C; Carval ho, L B. 2015. Indústria e Desenvolvimento Produtivo no Brasil. 1. ed. Esevier: Ro de Janeiro, v. 1. 712 p.

${ }^{\dagger}$ Professor de Economia e Coordenador do Centro de Estudos do Novo Desenvolvimentismo da ESP/FGV.

${ }^{\ddagger}$ Universidade Estadual de Maringá e bolsista de produtividade em pesquisa do ONPQ.
} 


\section{Introdução}

En economias abertas, déficits frequentes em transações correntes e o consequente endividamento externo que podem surgir implicam uma restrição relevante ao crescimento econômico. Tais déficits tendem a ocorrer quando, à medida que a renda nacional se eleva e o país passa a necessitar de um volume maior de importações, as receitas obtidas com as exportações não são suficientes para cust ear as compras externas. Nesse quadro, o país pode ter que reduzir o nível da demanda doméstica para diminuir o volume de importações, ajustar seu saldo em transações correntes (e consequentemente o balanço de pagamentos) e atenuar o endividamento externo (ou estancar a sua evolução). Essa redução na absorção doméstica desencoraja o investimento, o progresso tecnológico e a produtividade e aborta o processo de crescimento, tornando-o efêmero.

Édessa discussão que surgem os modelos de crescimento com restrição de balanço de pagamentos. Em sua versão original, Thirlwall (1979) destaca que o equilíbrio externo seria uma condição fundamental para o crescimento perene e estável da demanda e da produção, sendo que tal equilíbrio estaria intrinsecamente relacionado às elasticidades-renda das exportações e importações. A chamada Lei de Thirlwall estabelece que a taxa de crescimento compatível com o equilíbrio do balanço de pagamentos é dada pela relação entre as elasticidades-renda da demanda por exportações e importações, multiplicada pela taxa de crescimento da renda mundial. Logo, a conclusão desses modelos demonstra que a única solução segura para um crescimento mais rápido da demanda e da renda em consonância com o equilíbrio do balanço de pagamentos é uma mudança estrutural (isto é, da estrutura produtiva) na direção do aumento da elasticidade-renda da demanda por exportações e da redução da elasticidade-renda da demanda por importações.

Nesse sentido, Thirlwall segue a tradição estruturalista que define a composição setorial da produção como um fator primordial no processo de desenvolvimento econômico. Autores como Rosenstein-Podan (1943), Prebisch (1949), Lewis (1954), Postow (1956), Furtado (1961), Kaldor (1966) e Chenery et al. (1986) adotaram esse argumento direcionando sua análise para o papel da manufatura nesse processo.

No âmbito dessa discussão, e seguindo os trabalhos supracitados, Pasinetti (1981) empreendeu esforços para incorporar mudanças estruturais na determinação da taxa de crescimento econômico. Segundo o autor, alterações na estrutura produtiva induzem a diferentes taxas de crescimento econômico. Araújo e Lima (2007) se valeram da abordagem de Pasinetti (1981) para propor a Lei de Thirlwall Multissetorial, na qual formalizam que a taxa de crescimento depende não só das elasticidades setoriais, mas da composição setorial da economia, pois a elasticidade-renda de cada setor é ponderada pelo peso deste no total das exportações ou importações para o cálculo das elasticidades médias agregadas. Sendo assim, mesmo que as elasticidades setoriais sejam constantes e não haja nenhuma alteração no crescimento da renda mundial, um país pode crescer mais rapidamente se transferir recursos para a produção nos setores com maiores elasticidades-renda da demanda por exportações e importações.

Isso posto, o objetivo deste trabalho é analisar os reflexos da estrutura produtiva brasileira no comércio exterior mediante a estimativa das elasticidades-renda da demanda por exportações e importações dos diferentes setores da indústria de transformação. Para tanto, procura-se responder em que setores tais elasticidades são mais significativas e que, portanto, 
deveriam ter sua produção estimulada, de forma a possibilitar uma alteração positiva em sua composição set orial e o aumento da taxa de crescimento econômico do país. ${ }^{1}$

Para atender a este objetivo o trabalho divide-se, além desta introdução, em mais três seções. A seção 2 apresenta alguns aspectos teóricos dos modelos de crescimento com restrição de balanço de pagamentos. A terceira seção estima as elasticidades-renda da demanda por exportações e importações dos diferentes setores da indústria de transformação e suas agregações por intensidade tecnológica. A última seção conclui a pesquisa, destacando a importância da desconcentração das importações e a elevação dos investimentos nos setores da manufatura intensivos em conhecimento.

\section{A Teoria do Orescimento com Restrição de Balanço de Pagamentose a Estrutura Produtiva}

$\mathrm{Na}$ abordagem do crescimento econômico orientada pela demanda, as exportações se destacam porque são o único verdadeiro componente da demanda autônoma em um sistema econômico, visto que a alternativa seria a expansão dos gastos públicos e esses não podem crescer continuamente sob pena de gerar endividamento e reconhecidos desequilíbrios macroeconômicos. As exportações podem implicar um círculo virtuoso de crescimento, via aumento da produtividade e da geração de externalidades aos demais setores através da difusão de conhecimento e tecnologia, além de possibilitar o incremento da receita em moeda estrangeira e o financiamento das compras externas necessárias ao desenvolvimento, como os bens de capital que não são localmente produzidos, e aquelas resultantes do aumento do consumo que decorre da expansão da renda. ${ }^{2}$ Exportações modestas implicam crescimento econômico também modesto.

Assim, quando existem rendimentos crescentes, encadeamentos produtivos e aumento induzido da produtividade, o aumento das exportações pode ocasionar um círculo virtuoso de crescimento que proporciona aos países em desenvolvimento realizarem o catching up. Essas seriam características dos bens manufaturados com maior conteúdo tecnológico (Hirschman, 1958, Kaldor, 1966, Hausmann, Hwang e Rodrik, 2006, Razmi e Blecker, 2006). Além disso, uma das fontes de restrição ao crescimento, do lado da demanda, pode advir da evolução das operações da economia com o setor externo. Thirlwall (1979) detalha esse argumento através da formulação dos modelos de crescimento com restrição do balanço de pagamentos.

Segundo esse autor, a restrição relevante ao crescimento em uma economia aberta é imposta pelo balanço de pagamentos, pois à medida que o país vai crescendo a demanda por importações também se eleva, e essas devem ser custeadas, para evitar tal restrição, pelas receitas obtidas com as exportações. Do contrário, o país possivelmente precisará reduzir o nível da demanda doméstica para diminuir as importações e melhorar o resultado em transações correntes, desencorajando o investimento, o progresso tecnológico e o processo de crescimento, conforme já citado.

Porém, se um país expandir sua demanda no nível da capacidade produtiva existente sem incorrer em dificuldades no balanço de pagamentos, a necessidade de expansão de tal capacidade levará ao aumento do investimento e incremento do progresso tecnológico. Esse

\footnotetext{
${ }^{1}$ Escolhemos a indústria de transformação, entre o œnjunto de bens comercializáveis, em virtude de seu impacto sobre o processo de desenvolvimento econômico, conforme defendem autores supracitados neste artigo.

${ }^{2}$ Thirwall (2006, p. 533-537).
} 
cenário implica incentivos à demanda e em um círculo virtuoso de crescimento que pode aumentar a produtividade total da economia, com os fatores de produção migrando na direção de setores de alta produtividade e intensivos em learning-by-doing. O crescimento da demanda será portanto desigual entre os diversos setores e alterará os incentivos ao investimento nestes últimos, promovendo a expansão de alguns em detrimento de outros. Logo, ceteris paribus, se um país aumenta suas exportações e reduz suas importações de um determinado conjunto de produtos, estará estimulando o investimento e a participação do setor que os produz no valor adicionado agregado.

Para detalhar esse argumento, o modelo de Thirlwall (1979) parte de uma situação de igualdade entre exportações e importações (equilíbrio da balança comercial de bens e serviços) e, considerando o saldo comercial como uma aproximação para o resultado global do saldo em transações correntes, e, mais que isso, do próprio balanço de pagamentos, ou seja, excluindo-se a priori os fluxos de capitais e desconsiderando as rendas recebidas e enviadas ao exterior, o autor demonstra que a taxa de crescimento que um país pode alcançar, sem incorrer em desequilíbrio no balanço de pagamentos, é igual à taxa de crescimento das exportações, dividida pela elasticidade renda da demanda por importações. Como as exportações dependem da elasticidade-renda da demanda por exportações e da taxa de crescimento da renda mundial, temos que a taxa de crescimento que resulta no equilíbrio do balanço de pagamentos dependerá da taxa de crescimento da renda mundial, da elasticidade renda das exportações e da elasticidade renda das importações. Essa equação se constitui na chamada Lei de Thirlwall:

$$
y_{c e s}=\frac{\dot{x}}{\pi}=\frac{\varepsilon}{\pi} * y_{m}
$$

Onde $Y_{\infty e}$ é a taxa de crescimento de um país consistente com o equilíbrio intertemporal do seu saldo do balanço de pagamentos, $\dot{x}$. é a taxa de crescimento das exportações desse país, $\varepsilon$ é a elasticidade-renda de suas exportações, $\pi$ é a elasticidade renda de suas importações e $\dot{y}_{m}$ é a taxa de crescimento da renda mundial.

Tais elasticidades variam entre períodos e países porque dependem das características dos bens exportados e importados e da estrutura produtiva da economia, conforme argumentação apresentada a seguir.

Segundo os modelos estruturalistas, os países de desenvolvimento retardatário têm dificuldades para sofisticar a sua estrutura produtiva porque a demanda agregada é insuficiente para estimular o investimento necessário, não dispõem de poupança suficiente para fazêlo, não possuem acesso fácil às tecnologias disponíveis e sua difusão é dificultada por requerer certa base técnica previamente consolidada. Ademais, essas economias terminam explorando as suas vantagens comparativas, o que no curto prazo demonstra-se vantajoso, dado o retorno elevado e as facilidades em implementar tal estratégia (Prebisch, 1949). ${ }^{3}$ Assim, a estrutura produtiva nesses países tende a ser diversa da observada naqueles mais desenvolvidos: enquanto estes últimos se especializam na produção de bens com maior

\footnotetext{
${ }^{3}$ Autores como Furtado (1961), Lewis (1958 [1954]) e Posenstein-Podan (1943) estão entre os pioneiros na teoria estruturalista, destacando a relevância da mudança na estrutura produtiva em direção a manufatura œmo um aspecto fundamental no processo de desenvolvimento eœonômico.
} 
conteúdo tecnológico, os países em desenvolvimento se especializam na produção de bens primários, dadas suas vantagens comparativas na exportação destes produtos. ${ }^{4}$

O direcionamento das exportações para os bens primários e a decorrente especialização na produção dos mesmos estariam na origem da restrição ao crescimento oriunda dos desequilíbrios do balanço de pagamentos porque a elasticidade-renda da demanda por produtos primários seria inferior à dos produtos manufaturados, em função da Lei de Engel..$^{5}$ Essa lei estabelece que as variações na quantidade demandada dos diversos bens se alteram em função de mudanças no nível de renda, de acordo com a avaliação dos consumidores sobre o caráter essencial ou supérfluo dos produtos.

Fazendo a transposição de uma lei microeconômica, que explica o comportamento do consumidor, para essa discussão sobre estrutura produtiva, é possível afirmar que quando a renda de um país se eleva, a variação observada na demanda por bens primários é inferior à variação observada na demanda por bens manufaturados. Logo, um aumento na renda mundial provocaria um aumento menos que proporcional na demanda por produtos primários, e mais que proporcional na demanda por produtos manufaturados. O mesmo vale em relação às variações na renda local. Assim, economias que exportam bens primários e importam manufaturados teriam uma elasticidade-renda das exportações menor que a das importações, e um aumento da renda interna levaria a um déficit em transações correntes (a não ser que o crescimento da renda mundial fosse consideravelmente superior ao da renda interna), que deveria ser ajustado através de uma redução na absorção doméstica. ${ }^{6}$

Para se aproximar da realidade vigente nos países em desenvolvimento, outros fatores também passaram a ser considerados no modelo original de Thirwall (1979), por exemplo, o fluxo de capital entre os países, o serviço da dívida (Thirlwall e Hussain, 1982, McCombie e Thirlwall, 1997, Barbosa-Filho, 2001, e Moreno-Brid 2003).Este artigo adota a formulação simplificada da Lei de Thirlwall porque nosso enfoque é direcionado à análise da diferenciação entre as elasticidades-renda de exportação e import ação dos diversos setores. ${ }^{7}$

Em termos empíricos, McCombie e Thirlwall (1994) confirmam a existência da relação explicada pela Lei de Thirlwall, e mostram que um pré-requisito para aumentar a taxa de crescimento de um país é o relaxamento da restrição oriunda do desequilíbrio do balanço de pagamentos. Segundo os autores isso pode ser alcançado mediante políticas de estímulo ao aumento das elasticidades-renda das exportações e redução das elasticidades-renda das importações, o que decorreria de uma alteração da estrutura produtiva da economia em questão.

${ }^{4}$ Esse œnário também é explicado pelos modelos de doença holandesa (Corden and Neary, 1982; Palma, 2005; e Bresser-Pereira, 2008).

${ }^{5}$ Prebisch (1949) foi um dos precursores dessa discussão, ainda que seu argumento sobre a deterioração dos termos de troca para os países em desenvolvimento não tenha se confirmado.

${ }^{6}$ Cornwall (1977) descreve o crescimento econômico œmo um processo em movimento através da hierarquia das commodities, $\infty \mathrm{m}$ a demanda pelo produto dos vários setores sendo caracterizada por curvas de Engel, de forma que a composição da demanda e o crescimento econômico se afetam mutuamente.

${ }^{7}$ A formulação inicial do modelo também não incorpora a influência de mudanças nos preços relativos ou na taxa de câmbio sobre o resultado do balanço de pagamentos. Desdobramentos posteriores do modelo demonstram que tais elasticidades podem inclusive tornar-se endógenas em relação ao nível e às variações na taxa real de câmbio (Araujo e Lima, 2007; Missio e Jayme $\mathrm{k}$, 2011; Ferrari, Freitas e Barbosa Fllho, 2013; Bresser, Oreiro e Marconi, 2014). 
Portanto, embora o potencial de crescimento de uma economia seja determinado pela taxa de crescimento da demanda, a abordagem do crescimento com restrição de balanço de pagamentos reitera a importância de características relativas à composição dessa demanda e, por consequência, da of erta dos bens. Assim, se um país produz uma variedade de bens com diferentes elasticidades, sendo a elasticidade-renda total da economia calculada como a média das elasticidades de cada setor, ponderada por sua participação na estrutura produtiva, então uma mudança na estrutura produtiva da economia af eta a elasticidade-renda das importações e exportações, uma vez que diferentes taxas de crescimento da demanda para os diferentes setores resultam em diferentes taxas de crescimento da economia como um todo. Mudanças na composição setorial da economia, isto é, de sua estrutura produtiva, teriam repercussões sobre a taxa global de crescimento econômico.

Com base nesse raciocínio, Araújo e Lima (2007) desenvolveram um modelo multissetorial que resulta na Lei de Thirlwall Multissetorial. Nesse modelo, a taxa de crescimento de cada país é diretamente proporcional à taxa de crescimento das exportações. Essa proporcionalidade é inversamente relacionada à elasticidade-renda setorial da demanda por importações e diretamente proporcional à elasticidade-renda setorial da demanda por export ações. Em resumo, a taxa de crescimento depende da composição setorial da economia, pois a elasticidade-renda de cada setor é ponderada pelo peso desse setor no total das exportações ou importações.

Uma implicação do modelo multissetorial é que, mesmo que as elasticidades setoriais sejam constantes e não haja nenhuma alteração no crescimento da renda mundial, um país pode crescer mais rapidamente se transferir recursos para os setores com maiores elasticidades-renda da demanda por exportações e se reduzir, em termos relativos, o investimento em setores com maiores elasticidades-renda da demanda por importações.

Analogamente, os autores mostram que, se houver um aumento na renda mundial, um país vai se beneficiar mais quanto maiores forem suas elasticidades-renda da demanda por exportações setoriais e mais baixas forem suas elasticidades-renda da demanda por importações nos diferentes setores. De um ponto de vista da formulação de políticas de desenvolvimento, essa especificação multissetorial do modelo permite a identificação de setores estratégicos entre aqueles que produzem bens comercializáveis para a promoção do crescimento da economia.

Os resultados teóricos propostos por Araújo e lima (2007) foram corroborados empiricamente por Gouvêa e Lima (2009). Os autores aplicam o modelo multissetorial para alguns países da América Latina (Argentina, Brasil, Colômbia e México) e alguns países asiáticos (Coreia do Sul, Malásia, Flipinas e Ongapura), entre 1962 e 2006. Os resultados encontrados mostram que, de forma geral, os setores intensivos em tecnologia têm uma elasticidade-renda da demanda por exportações mais elevadas, embora as elasticidades-renda da demanda por importações não varie muito entre os diferentes setores.

A partir da estimativa das elasticidades setoriais, a taxa de crescimento econômico limitada pelo balanço de pagamentos é calculada com base na soma das elasticidades setoriais ponderadas pela participação de cada setor no total das exportações e importações. Os resultados evidenciam que essa taxa de crescimento oriunda do modelo multissetorial é, em geral, próxima à resultante da aplicação do modelo mais simples da Lei de Thirlwall, bem como se aproxima da taxa de crescimento ef etiva das economias.

Dando continuidade à investigação empírica, os autores usam as elasticidades setoriais para estimarem ano a ano a evolução das elasticidades-renda agregadas das exportações e importações, com o interesse de identificar $\infty$ mo as mudanças estruturais impactam a taxa de crescimento econômico limitada pelo balanço de pagamentos. Para a América Latina, exceto 
México, a razão das elasticidades-renda setoriais ponderadas da demanda por exportações e importações pouœ mudou durante o período estudado, mas na Ásia, essa razão aumentou significativamente, afetando de forma positiva a taxa de crescimento limitada pelo balanço de pagamentos nesses países.

Também em um estudo mais amplo de 29 países desenvolvidos e em desenvolvimento, utilizando essa abordagem setorial, Amoli, Porcile e Povira (2010) demonstraram que os países em desenvolvimento que conseguiram reduzir a diferença de renda em relação aos países desenvolvidos foram os que conseguiram transformar suas estrut uras produtivas, isto é, que conœentraram esforços em produtos com maior elasticidaderenda da demanda por exportações.

Feitas essas considerações a respeito dos modelos de crescimento com restrição de balanço de pagamentos e a Lei de Thirlwall Multissetorial, as próximas seções estimam para 0 Brasil as elasticidades-renda da demanda por exportações e importações agregadas por intensidade tecnológica e setoriais.

\section{Estimativa das Basticidades-Renda da Demanda por Exportaçõese Importações}

\subsection{Base de dados}

Esta seção apresenta a estimativa da elasticidade-renda da demanda por importações e exportações brasileiras em nível mais agregado, para o conjunto da manufatura e segundo classificação setorial apresentada mais abaixo. O modelo estimado segue as seguintes especificações:

$$
\begin{aligned}
& x_{i t}=c+\varphi\left(\operatorname{rer}_{t}\right)+\varepsilon\left(y^{*}{ }_{t}\right)+e_{t} \\
& m_{i t}=c+\psi\left(\operatorname{rer}_{t}\right)+\pi\left(y_{t}\right)+e_{t}
\end{aligned}
$$

sendo que $m$ representa o quantum de importações, $c$ a constante exógena, $\psi$ a elasticidade-preço da demanda por importações, rer é a taxa de câmbio real (expressa como o preço doméstico da moeda estrangeira), $\pi$ a elasticidade-renda da demanda por importações, $y$ é o PBB real doméstico, e o erro aleatório, $x$ é o quantum de exportações, $\varphi$ a elasticidade-preço da demanda por exportações, $\varepsilon$ é a elasticidade-renda da demanda por exportações, $y^{\star}$ é o PIB real mundial, $i$ são os diferentes setores da indústria de transformação e $t$ é o período de tempo anual.

Os dados utilizados nessa pesquisa refer entes às exportações dos difer entes setores da indústria de transformação (de modo a possibilitar uma análise que considere a relevância da estrutura produtiva) têm como fonte o Programa de Análise da Dinâmica Industrial (Padi) da Cepal, concebido de forma a permitir o estudo da evolução da estrutura industrial em países da América Latina e Caribe. Para alcançar esse objetivo, o Padi oferece aos usuários uma base de dados sobre a indústria e um sistema de processamento adaptado para a sua análise. A base de dados utilizada no Padi foi desenvolvida pela Unidade de Desenvolvimento Industrial e Tecnológico, desde 1993, com o objetivo de melhorar a sua capacidade de análise da evolução e os processos de transformação que têm caracterizado a indústria manufatureira na região. Essa base contém dados de 26 países da América Latina e do Caribe, com variáveis relativas à estrutura industrial da economia, abrangendo o período de 1970 até o último ano em que as estatísticas estão disponíveis para cada país.

As demais variáveis, quais sejam, PIB mundial real, PIB brasileiro real e taxa de câmbio real, foram calculadas com base nos dados do International Financial Statistics (IFS) do Fundo Monetário Internacional. 
O Padi apresenta os dados das exportações industriais divididos em 28 setores, sendo eles produtos alimentícios, bebidas, tabaco, têxteis, vestuário, produtos de couro, calçados, produtos de madeira, mobiliário, papel e celulose, impressão e publicações, indústria química, outros químicos, refinarias de petróleo, produtos de petróleo e carvão, produtos de borracha, produtos plásticos, cerâmica, vidro, outros minerais não metálicos, ferro e aço, metais não ferrosos, produtos de metal, máquinas não elétricas, máquinas elétricas, equipamento de transporte, inst rumentos cient íficos e profissionais e outras manufaturas.

Esses setores são agrupados ainda em três classes de produtos segundo a intensidade tecnológica, sendo elas os produtos intensivos em recursos naturais, os produtos intensivos em trabalho e os produtos intensivos em engenharia, ciências e conhecimento. $O$ detalhamento dessa subdivisão pode ser explicado como a seguir.

a) Indústria intensiva em recursos naturais: o fator principal de competitividade é o acesso a recursos naturais abundantes existentes no país. Encontram-se nesse grupo as indústrias de produtos alimentícios, de bebidas e de tabaco, de produtos de couro, exceto calçados e vestuário, de produtos de madeira, cortiça e material trançado, exceto móveis, de ferro e aço, de celulose, papel e papelão, de refino de petróleo, de produtos diversos de petróleo e carvão, de produtos de minerais não metálicos, bem como a indústria básica de metais não ferrosos.

b) Indústria intensiva em trabalho: o fator mais relevante de competitividade é a disponibilidade de mão de obra com custos reduzidos relativamente a outros países. Indui a indústria têxtil, de vestuário e de calçados, de móveis, de plástico, publicação e imprensa, cerâmica, e outras indústrias.

c) Indústria intensiva em engenharia, ciência e conhecimento: o principal fator de competitividade é a rápida aplicação dos avanços científicos às tecnologias industriais. Nesse grupo, estão as empresas que fabricam produtos de metal, máquinas não elétricas e elétricas, equipamento de transporte, instrumentos científicos e indústria química. ${ }^{8}$

\subsection{Pesultados para as exportações}

Primeiramente procedeu-se à estimativa das elasticidades-renda da demanda dos setores da indústria de transformação, agregados segundo a intensidade tecnológica, isto é, da indústria intensiva em recursos naturais, intensiva em trabalho e intensiva em engenharia, ciências e conhecimento. Os resultados encontram-se na tabela 1.

Observa-se que a elasticidade-renda da demanda dos produtos exportados pela indústria intensiva em engenharia, ciência e conhecimento é maior que as elasticidades dos demais ramos da indústria de transformação. Esse resultado sugere, à luz das teorias de crescimento com restrição de balanço de pagamentos, que uma pauta de exportação concentrada em produtos com maior conteúdo tecnológico pode reduzir tal restrição e possibilitar a ocorrência de taxas de crescimento do PIB mais elevadas do que out ras indústrias intensivas em trabalho ou em commodities, como é o caso no Brasil. O gráfico 1 ilustra a participação média de cada grupo nas exportações da indústria de transformação segundo a classificação Padi.

\footnotetext{
${ }^{8}$ Destaque-se que o Padi não considera a indústria química œmo pertencendo à indústria intensiva em engenharia, ciência e conhecimento, mas aqui optou-se por incluí-la nesta cat egoria, como também o fazem Nassif, Feijó e Araújo (2012).
} 
Tabela 1 - Função exportação: indústria de transformação por intensidade tecnológica (1980 a 2008)

\begin{tabular}{|c|c|c|c|}
\hline \multicolumn{4}{|c|}{ Total da indústria de transformação } \\
\hline & $\phi$ & $\varepsilon$ & Constante \\
\hline Coeficiente & 0,52 & 1,13 & $-5,82$ \\
\hline Desvio padrão & 0,28 & 0,07 & 2,02 \\
\hline Testet & 1,81 & 16,36 & $-2,89$ \\
\hline \multicolumn{4}{|c|}{ Intensiva em recursos naturais } \\
\hline & $\phi$ & $\varepsilon$ & Constante \\
\hline Coeficiente & 0,26 & 1,05 & $-3,23$ \\
\hline Desvio padrão & 0,14 & 0,08 & 1,36 \\
\hline Testet & 1,87 & 12,72 & $-2,38$ \\
\hline \multicolumn{4}{|c|}{ Indústria intensiva em trabalho } \\
\hline & $\phi$ & $\varepsilon$ & Constante \\
\hline Coeficiente & 0,99 & 0,94 & $-1,71$ \\
\hline Desvio padrão & 0,32 & 0,04 & 0,66 \\
\hline Testet & 3,12 & 23,61 & $-2,58$ \\
\hline \multicolumn{4}{|c|}{ Indústria intensiva em engenharia, ciência e conhecimento } \\
\hline & $\phi$ & $\varepsilon$ & Constante \\
\hline Coeficiente & 0,41 & 1,41 & $-6,27$ \\
\hline Desvio padrão & 0,27 & 0,07 & 1,14 \\
\hline Testet & 1,50 & 20,5 & $-5,46$ \\
\hline
\end{tabular}

Fonte: 日aboração própria œm base nos dados do Padi. Nota: Todas as variáveis estão em logaritmo natural.

Observa-se que embora a indústria intensiva em engenharia, ciência e conhecimento possua maior elasticidade-renda da demanda, representa apenas 30\% das exportações da indústria de transformação. Já o grupo dos produtos da indústria intensiva em recursos naturais, apesar de apresentar menor elasticidade-renda da demanda, compõe $60 \%$ de tais exportações.

Gráfico 1 - Participação em 2008 das exportações por intensidade tecnológica no total das exportações da indústria de transformação

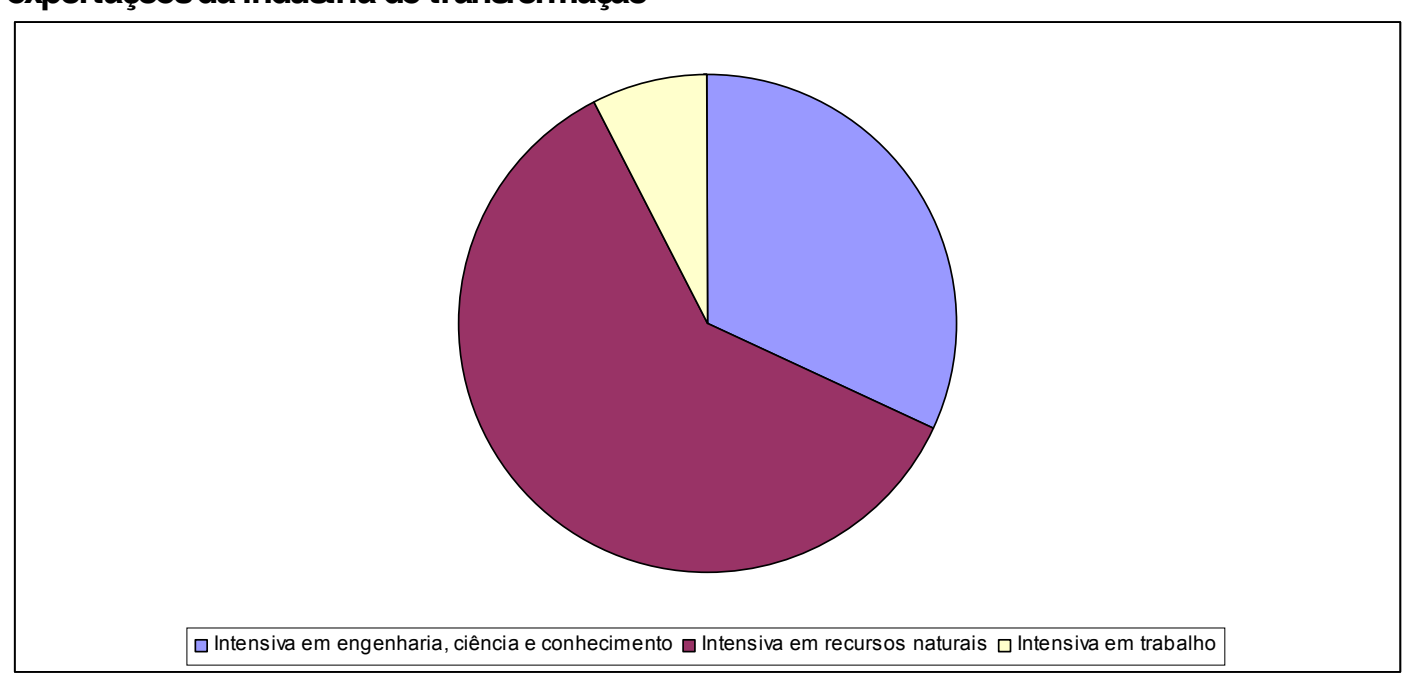

Fonte: Eaboração própria com base nos dados do Padi.

A composição das exportações setoriais no total da indústria de transformação é importante, pois, segundo a Lei de Thirlwall Multissetorial, as elasticidades setoriais devem ser ponderadas pelo peso de cada setor nas exportações totais. Isso significa que, mesmo com as elasticidades setoriais mantendo-se constantes, a taxa de crescimento compatível com o equilíbrio externo pode ser alterada devido à mudança estrutural proveniente de modificações 
na composição das export ações na direção de setores com maior ou menor elasticidade-renda da demanda externa pelos produtos nacionais.

Com o intuito de investigar em nível mais desagregado quais são os setores com maior elasticidade-renda da demanda por exportações, foram estimadas tais elasticidades para os 28 setores da indústria de transformação, segundo a classificação Padi, além da elasticidade total da indústria de transformação. Os resultados estão apresentados no gráfico 2.

O gráfico 2 evidencia que os setores de produtos alimentícios, bebidas, têxtil, vestuário, calçados, refino de petróleo e cerâmica foram os que apresentaram as menores elasticidades-renda da demanda por exportações. Destaque-se que dentre esses produtos o setor de alimentos e refino de petróleo são bastante significativos dentro da pauta de exportações da indústria de transformação, representando mais de $30 \%$ desta lá outros produtos que possuem alta elasticidade-renda da demanda possuem baixa representatividade dentro da mesma pauta. Essa participação dos diferentes setores nas exportações da indústria de transformação pode ser vista no gráfico 3.

A tabela 2 associa as elasticidades-renda da demanda setorial pelas exportações brasileiras aos pesos dos diferentes setores no total de exportações da indústria de transformação. Os dados estão ordenados segundo a magnitude das elasticidades-renda da demanda por exportações. ${ }^{9}$

\section{Gráfico 2 - Easticidadesrenda da demanda por exportações setoriais(1980-2008)}

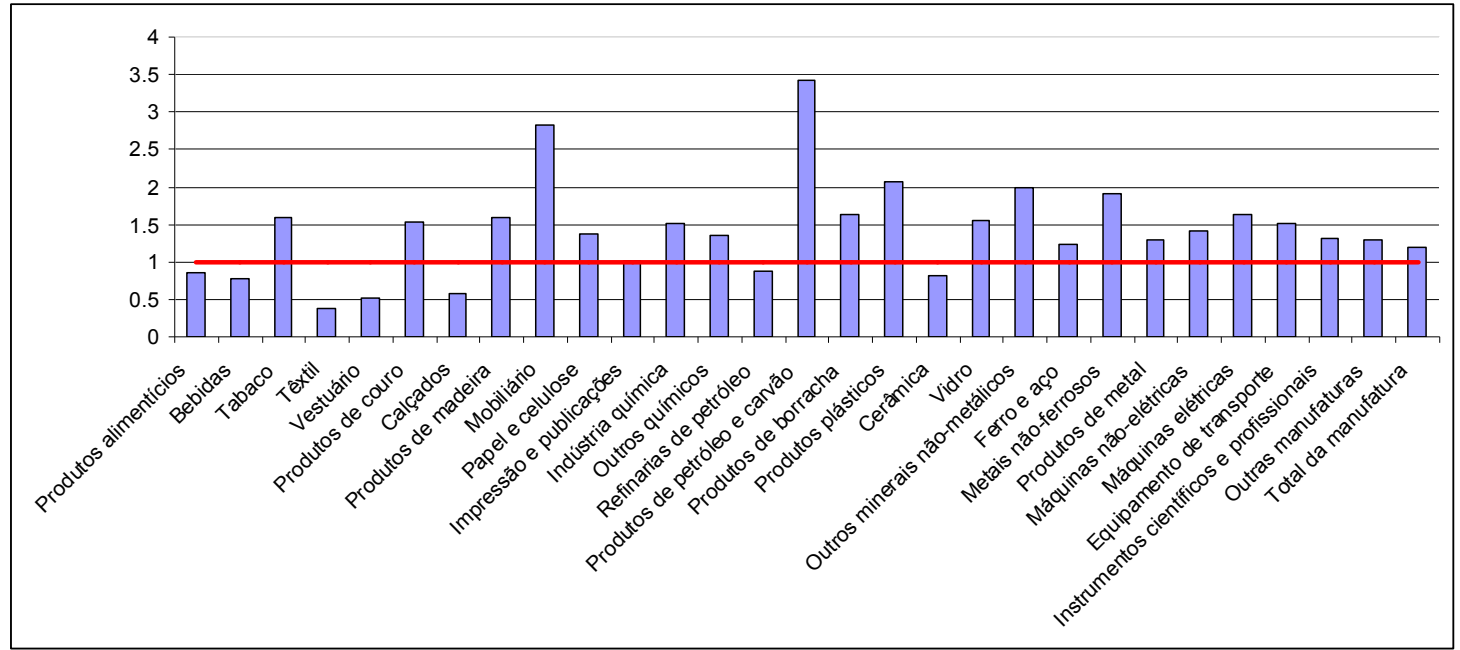

Fonte: Eaboração própria com base nos dados do Padi.

${ }^{9}$ Outra análise interessante que poderia ser extraída desses dados é a investigação acerca da heterogeneidade estrutural, no entanto o enfoque da pesquisa está nas elasticidades-renda da demanda por exportaçães e importações, pois a primeira investigação já tem sido explorada por diversos autores, a saber: Nassif et al. (2014); Oreiro e Feijó (2010); Marconi et al. (2014) e outros. 
Gráfico 3 - Participação das exportações setoriais nas exportações totais da indústria de transformação (2008)

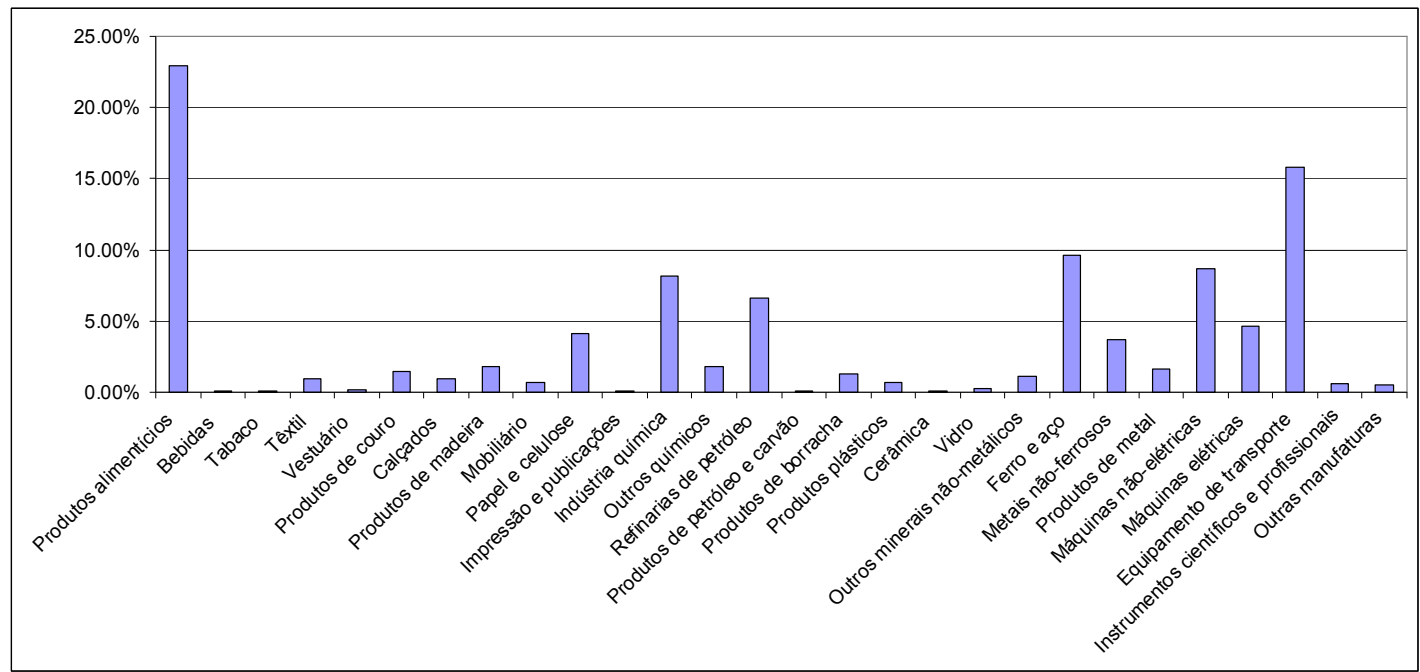

Fonte: Eaboração própria com base nos dados do Padi.

Analisando a tabela 2, é possível observar que os dez produtos com maior elasticidaderenda da demanda não representam $15 \%$ das exportações da indústria de transformação, enquanto os dez produtos $\infty \mathrm{m}$ as menores elasticidades-renda da demanda representam aproximadamente $45 \%$ das exportações da indústria de transformação. Praticamente todos os grupos de produtos intensivos em tecnologia e conhecimento estão situados acima da mediana na tabela e, portanto, sua elasticidade-renda é razoavelmente elevada (a mínima neste grupo atinge 1,3). Destacam-se neste grupo os setores de equipamentos de transportes, indústria química, outros químicos e máquinas elétricas que representam $37 \%$ das exportações da indústria de transformação e estão entre os produtos œm altas elasticidades-renda da demanda por exportações. Uma participação mais significativa desses setores na pauta de exportações possivelmente contribuiria para alterar a estrutura produtiva e elevar a taxa de crescimento da economia brasileira de forma consistente, tanto por diminuir as restrições oriundas do balanço de pagamentos como pelo estímulo à produtividade e à intensidade dos encadeamentos produtivos que gerariam. 
Tabela 2 - Basticidade-renda versus composição setorial das exportações da indústria de transformação brasileira (1980-2008)

\begin{tabular}{|c|c|c|}
\hline Setor & $\begin{array}{l}\text { Easticidade-renda da } \\
\text { demanda }\end{array}$ & $\begin{array}{l}\text { Peso do setor na composição } \\
\text { das exportaçōes da indústria } \\
\text { de transformação em } 2008\end{array}$ \\
\hline Produtos de petróleo e carvão & 3,43 & $0,05 \%$ \\
\hline Mobiliário & 2,83 & $0,67 \%$ \\
\hline Produtos plásticos & 2,06 & $0,73 \%$ \\
\hline Outros minerais não metálicos & 1,99 & $1,09 \%$ \\
\hline Metais não ferrosos & 1,91 & $3,66 \%$ \\
\hline Máquinas não elétricas & 1,63 & $4,65 \%$ \\
\hline Produtos de borracha & 1,62 & $1,33 \%$ \\
\hline Tabaco & 1,60 & $0,07 \%$ \\
\hline Produtos de madeira & 1,59 & $1,81 \%$ \\
\hline Vidro & 1,56 & $0,23 \%$ \\
\hline Produtos de couro & 1,54 & $1,49 \%$ \\
\hline Equipamentos de transportes & 1,52 & $15,81 \%$ \\
\hline Indústria química & 1,51 & $8,15 \%$ \\
\hline Máquinas elétricas & 1,41 & $8,66 \%$ \\
\hline Outros químicos & 1,41 & $4,09 \%$ \\
\hline Papel e celulose & 1,36 & $0,77 \%$ \\
\hline Instrumentos científicos & 1,31 & $0,63 \%$ \\
\hline Outros manuf aturados & 1,30 & $0,52 \%$ \\
\hline Produtos de metais & 1,30 & $1,66 \%$ \\
\hline Ferro e aço & 1,23 & $9,61 \%$ \\
\hline Imprensa e publicação & 1,02 & $0,08 \%$ \\
\hline Pefinaria de pet róleo & 0,87 & $6,65 \%$ \\
\hline Produtos alimentícios & 0,86 & $23,4 \%$ \\
\hline Cerâmica & 0,82 & $0,07 \%$ \\
\hline Bebidas & 0,77 & $0,08 \%$ \\
\hline Calçados & 0,58 & $0,98 \%$ \\
\hline Vestuário & 0,52 & $0,18 \%$ \\
\hline Têxtil & 0,37 & $0,95 \%$ \\
\hline
\end{tabular}

Fonte: Eaboração própria com base nos dados do Padi.

\subsection{Pesultados para as importações}

Quanto às importações, as elasticidades-renda da demanda dos produtos importados pela indústria de transformação agregados por intensidade tecnológica são apresentadas na tabela 3. 
Tabela 3 - Função importação para a indústria de transformação por intensidade tecnológica (1980-2008)

\begin{tabular}{|c|c|c|c|}
\hline \multicolumn{4}{|c|}{ Total da indústria de transformação } \\
\hline & $\psi$ & $\pi$ & Constante \\
\hline Coeficiente & $-0,59$ & 1,28 & $-0,45$ \\
\hline Desvio padrão & 0,35 & 0,09 & 1,79 \\
\hline Testet & $-1,67$ & 13,92 & $-0,25$ \\
\hline \multicolumn{4}{|c|}{ Intensiva em recursos naturais } \\
\hline & $\psi$ & $\pi$ & Constante \\
\hline Coeficiente & $-0,53$ & 1,18 & $-0,43$ \\
\hline Desvio padrão & 0,33 & 0,08 & 1,70 \\
\hline Testet & $-1,58$ & 13,38 & $-0,25$ \\
\hline \multicolumn{4}{|c|}{ Indústria intensiva em trabalho } \\
\hline & $\psi$ & $\pi$ & Constante \\
\hline Coeficiente & $-0,77$ & 1,32 & $-0,43$ \\
\hline Desvio padrão & 0,34 & 0,09 & 1,70 \\
\hline Testet & $-2,28$ & 13,28 & $-0,25$ \\
\hline \multicolumn{4}{|c|}{ Indústria intensiva em engenharia, ciência e conhecimento } \\
\hline & $\psi$ & $\pi$ & Constante \\
\hline Coeficiente & $-0,61$ & 1,56 & $-1,48$ \\
\hline Desvio padrão & 0,38 & 0,08 & 1,93 \\
\hline Testet & 1,60 & 17,55 & $-0,76$ \\
\hline
\end{tabular}

Fonte: Eaboração própria com base nos dados do Padi. Nota: Todas as variáveis estão em logaritmo natural.

Uma primeira constatação a partir dos dados da tabela 3 é a maior magnitude que as elasticidades-renda dos produtos importados pela indústria de transformação apresentam, independente da agregação, em relação ao mesmo tipo de elasticidade dos produtos exportados por essa indústria (tabela 2).

Comparando a magnitude das elasticidades-renda da demanda por importações nas três agregações setoriais de produtos da indústria de transformação observa-se que, assim como nos produtos exportados, a elasticidade dos setores da indústria intensiva em engenharia, ciência e conhecimento é a maior, seguida da indústria intensiva em trabalho e da intensiva em recursos naturais.

A participação das importações desses três setores no total das importações da indústria de transformação pode ser observada no gráfico 4.

Observa-se no gráfico 4 que o setor intensivo em engenharia, ciência e conhecimento responde por $70 \%$ das importações da indústria de transformação, seguido pelo setor intensivo em recursos naturais e, por fim, intensivo em trabalho.

Comparando o gráfico 4 com o gráfico 1, que mostra a participação em 2008 das exportações por intensidade tecnológica, nota-se um padrão de comércio adverso do ponto de vista tecnológico. Se, pelo lado das exportações, observa-se uma maior importância relativa dos produtos intensivos em recursos nat urais e em trabalho, do lado das importações são os produtos intensivos em engenharia, ciência e conhecimento que têm a maior participação relativa nas importações do total da indústria de transformação. Segundo o modelo teórico, esse perfil da composição das exportações e importações brasileiras implicaria uma relação entre as elasticidades-renda de exportação e importação de baixa magnitude e maiores restrições ao crescimento econômico. As estimativas para as elasticidades-renda dos grupos de produtos agregados conforme descrição acima parecem confirmar essa suposição. 


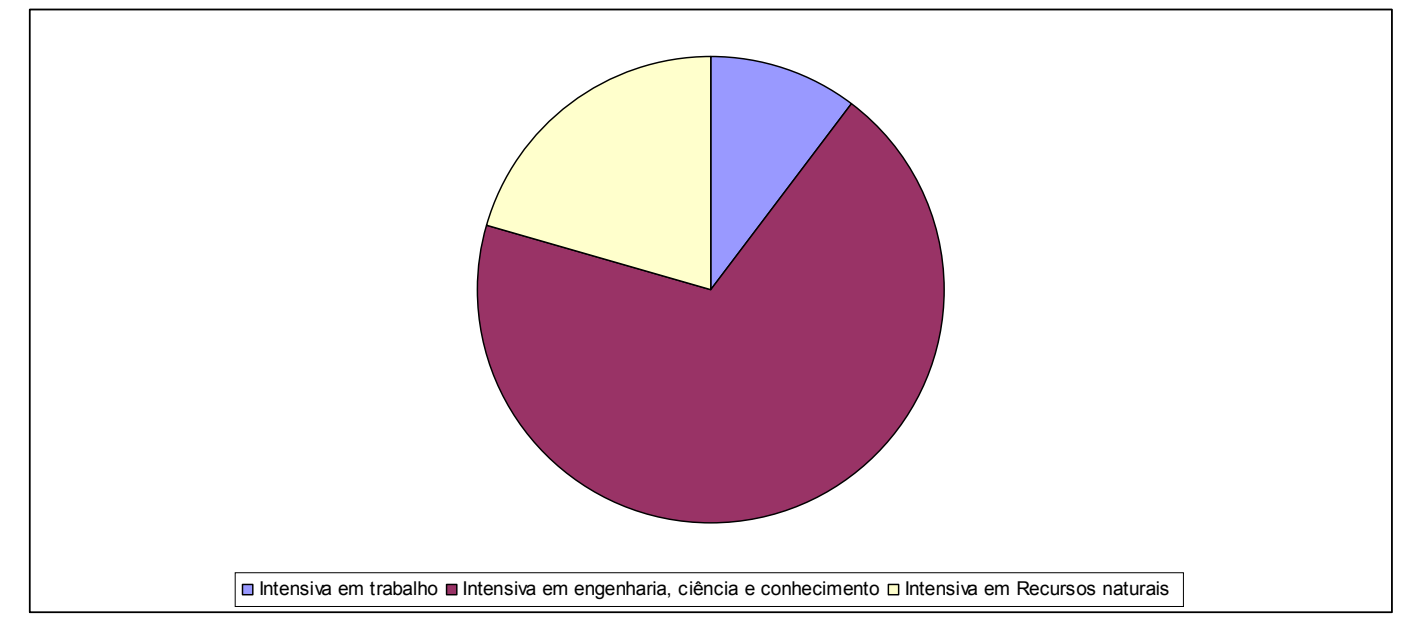

Fonte: Eaboração própria com base nos dados do Padi.

Para uma análise mais detalhada das elasticidades-renda da demanda por importações na indústria de transformação, o gráfico 5 apresenta o cálculo dessas elasticidades para os 28 setores da referida indústria.

Comparando o gráfico 5 com o gráfico 2, destaca-se que existe um número maior de grupos de produtos que apresenta elasticidade-renda das importações bastante elevada (superior a dois) e um número menor de grupos com demanda inelástica (inferior a um), confirmando que nossas importações são mais sensíveis a variações na renda que as exportações e que, por decorrência, uma mudança na estrutura produtiva da economia brasileira ajudaria a relaxar a restrição oriunda do balanço de pagamentos e elevaria a taxa de crescimento compatível com o seu equilíbrio.

O gráfico 6 apresenta a participação das importações dos 28 setores relacionados acima nas importações totais da indústria de transformação brasileira, evidenciando novamente um padrão oposto daquele apresentado pelas exportações. Os setores com maior participação nas importações da indústria de transformação são os setores da indústria química, máquinas não elétricas e elétricas e equipamentos de transporte. Estes são justamente os setores que pertencem à indústria intensiva em engenharia, ciência e conhecimento, que ao possuírem, salvo exceções, maior intensidade na relação capital/trabalho e maior sofisticação tecnológica em seus processos produtivos, têm maior capacidade de promover efeitos de encadeamento para frente e para trás e, portanto, de gerar maiores efeitos multiplicadores de renda e emprego, bem como de produzir e difundir inovações para o restante da economia, conforme já argument ado na discussão teórica. Assim, esses setores são relevantes para a maximização dos ganhos de produtividade nas economias e a sustentação do crescimento econômico no longo prazo. Porém, por contradição, são os mais relevantes na pauta de importações de nossa indústria de transformação, pois concentram $62 \%$ da mesma. 
Gráfico 5 - Easticidadesrenda da demanda por importações setoriais(1980-2008)

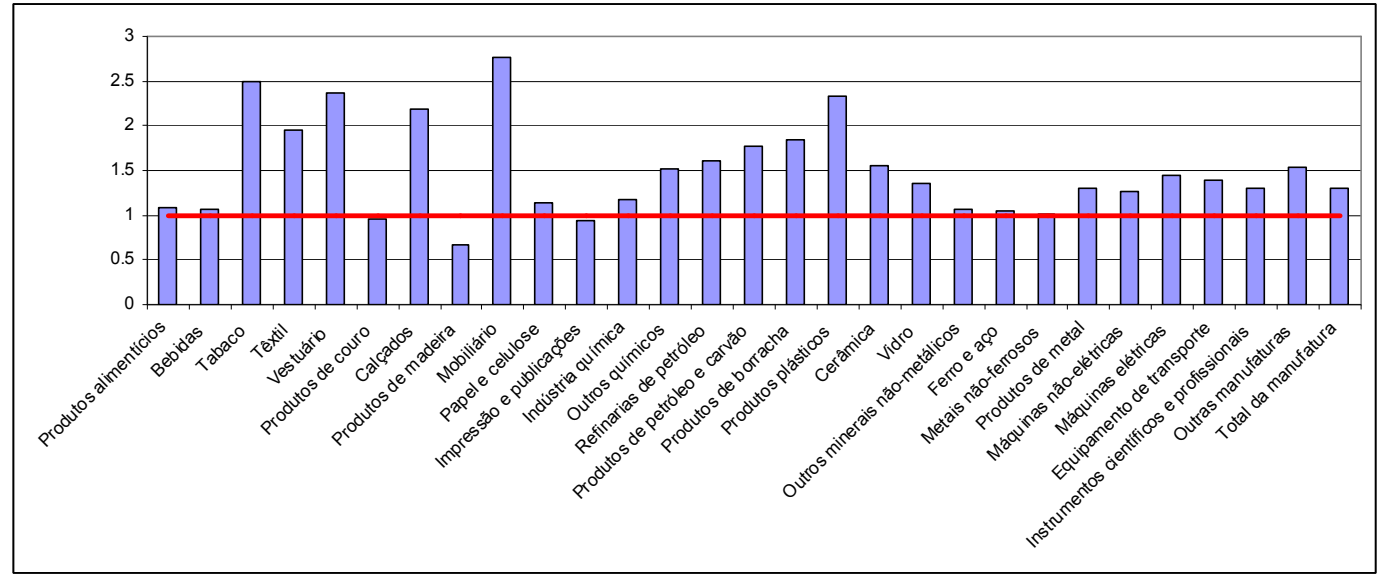

Fonte: Eaboração própria com base nos dados do Padi.

Gráfico 6 - Participação das importações setoriais nas importações totais da indústria de transformação (2008)

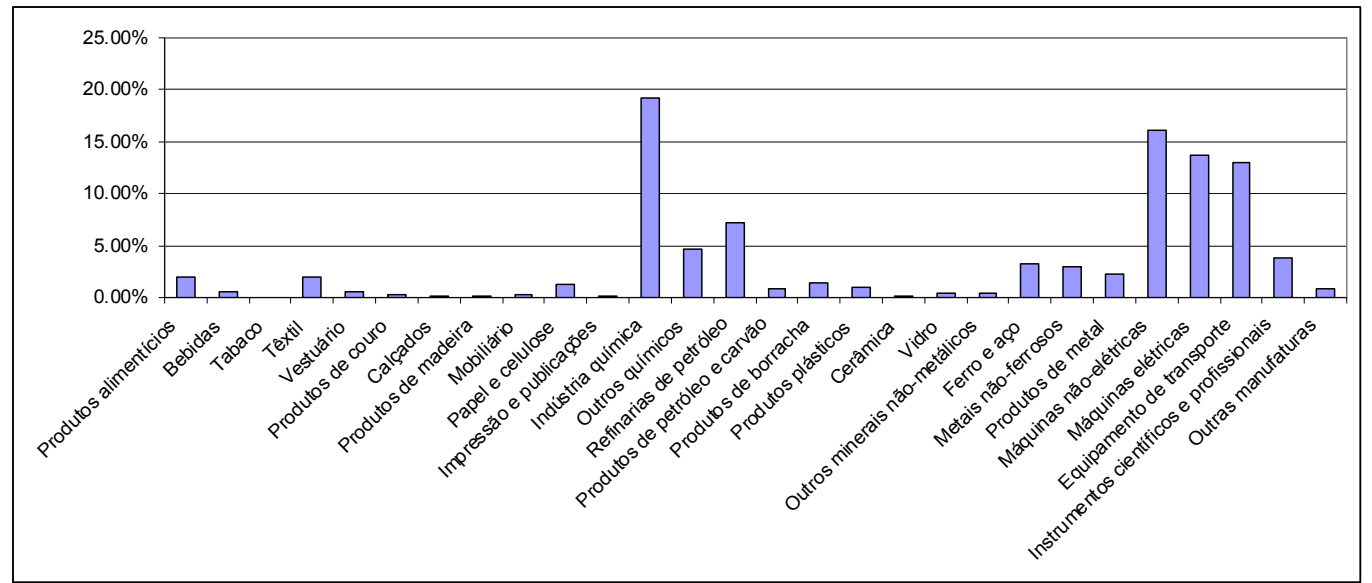

Fonte: Eaboração própria com base nos dados do Padi.

Por fim a tabela 4 associa os resultados apresentados nos gráficos 5 e 6, possi bilitando a comparação das elasticidades-renda da demanda por importações setoriais œm o peso de cada setor no total de importações da indústria de transformação brasileira.

Observa-se que os 10 produtos com maior elasticidade-renda da demanda por importações representam menos de $20 \%$ do total de compras externas da indústria de transformação. Já os 10 produtos com as menores elasticidades-renda da demanda representam aproximadamente $30 \%$ das importações da indústria de transformação. Portanto, a pauta está concentrada em produtos cuja elasticidade possui magnitude intermediária (em termos relativos, segundo essa classificação adotada para os setores), porém é al ta de qualquer forma, por ser superior a um nestes casos. 
Tabela 4 - Easticidade-renda versus composição setorial das importações da indústria de transformação brasileira (1980-2008)

\begin{tabular}{|c|c|c|}
\hline Setor & $\begin{array}{l}\text { Basticidade-renda da } \\
\text { demanda }\end{array}$ & $\begin{array}{l}\text { Peso do setor na composição } \\
\text { da indústria de transformação } \\
\text { em } 2008\end{array}$ \\
\hline Mobiliário & 2.77 & $0.29 \%$ \\
\hline Tabaco & 2.49 & $0.00 \%$ \\
\hline Vestuário & 2.37 & $0.62 \%$ \\
\hline Produtos plásticos & 2.33 & $1.04 \%$ \\
\hline Calçados & 2.19 & $0.12 \%$ \\
\hline Têxtil & 1.95 & $2.03 \%$ \\
\hline Produtos de borracha & 1.85 & $1.46 \%$ \\
\hline Produtos de petróleo e carvão & 1.77 & $0.79 \%$ \\
\hline Pefinarias de petróleo & 1.61 & $7.19 \%$ \\
\hline Outros químicos & 1.52 & $4.60 \%$ \\
\hline Cerâmica & 1.56 & $0.07 \%$ \\
\hline Outrasmanufaturas & 1.53 & $0.90 \%$ \\
\hline Máquinas elétricas & 1.44 & $13.69 \%$ \\
\hline Equipamento de transporte & 1.4 & $13.04 \%$ \\
\hline Vidro & 1.35 & $0.42 \%$ \\
\hline Produtos de metal & 1.31 & $2.25 \%$ \\
\hline Instrumentos científicos & 1.3 & $3.84 \%$ \\
\hline Máquinas não elétricas & 1.26 & $16.08 \%$ \\
\hline Indústria química & 1.17 & $19.24 \%$ \\
\hline Papel e celulose & 1.14 & $1.26 \%$ \\
\hline Produtos alimentícios & 1.08 & $2.01 \%$ \\
\hline Bebidas & 1.07 & $0.59 \%$ \\
\hline Outros minerais não metálicos & 1.06 & $0.39 \%$ \\
\hline Ferro e aço & 1.05 & $3.28 \%$ \\
\hline Metais não ferrosos & 1.01 & $2.91 \%$ \\
\hline Produtos de couro & 0.96 & $0.32 \%$ \\
\hline Impressão e publicações & 0.94 & $0.16 \%$ \\
\hline Produtos de madeira & 0.66 & $0.07 \%$ \\
\hline
\end{tabular}

Fonte: Eaboração própria com base nos dados do Padi.

No que se refere às menores elasticidades-renda da demanda por importações, destacam-se os produtos de couro, impressão e publicação e os produtos de madeiras, os alimentícios, bebidas, outros minerais não metálicos, ferro e aço e metais não ferrosos. 
Os produtos do grupo da indústria intensiva em engenharia, ciência e conhecimento são justamente aqueles cujas elasticidades situam-se entre as de magnitude intermediária, mas œmo sua participação nas importações totais é elevada (œnforme citado anteriormente), indicando um volume também elevado de importações, a elasticidade-renda agregada do grupo termina sendo a mais alta.

Portanto, o problema de nossa pauta de importações é, mais que a concentração de importações nos produtos com elasticidade-renda mais elevada, a concentração em alguns poucos grupos œm elasticidade-renda que de toda forma é superior a um e que possuem um conteúdo tecnológico mais sofisticado. Ressalta-se novamente que essa pauta restringe o desenvolvimento da economia brasileira não só pela influência sobre o resultado do balanço de pagamentos, mas também pelo impacto que o vazamento da demanda para o exterior gera sobre o incentivo ao investimento em setores de maior cont eúdo tecnológico, que geram mais externalidades positivas e possuem maior capacidade de gerar encadeamentos para os demais setores da economia brasileira.

\section{Considerações Finais}

Neste artigo buscou-se analisar, a partir do modelo teórico de crescimento com restrições oriundas do balanço de pagamentos e dos modelos estruturalistas que pressupõe a relevância da composição setorial da produção para o processo de desenvolvimento, algumas características da pauta de comércio exterior brasileiro e sua possível contribuição para o crescimento dessa economia.

Mais especificamente, partiu-se do pressuposto de que os setores exibem diferentes elasticidades-renda da demanda por exportações e importações, e que a relação entre tais elasticidades pode alterar o resultado do balanço de pagamentos, e este por fim pode implicar em restrições ao crescimento econômico perene e consistente. Também se considerou que variações na composição da demanda por exportações e importações podem gerar mudanças na produção e investimento nos diversos setores, e por consequência na estrutura produtiva da economia. Argumentou-se, adicionalmente, que os setores que produzem bens com maior conteúdo tecnológico possuem melhor capacidade para estimular o crescimento devido aos ganhos de produtividade, externalidades e aos encadeamentos produtivos que geram, e que os setores que produzem tais bens estão associados à manufatura (indústria de transformação), a qual, por conseguinte, foi privilegiada em nossa análise.

Para discutir tal influência da pauta de comércio exterior sobre o processo de crescimento, foram estimadas as elasticidades-renda da demanda por exportações e importações nos diferentes setores da indústria de transformação. As elasticidades associadas às importações mostraram-se mais elevadas que as das exportações, o que por si já se constitui em uma restrição ao crescimento associada ao balanço de pagamentos, mas os resultados mais relevantes deste artigo demonstram que tanto as exportações como as importações de bens cujo processo produtivo é intensivo em engenharia, ciência e conhecimento possuem maiores elasticidades-renda da demanda tanto por exportações como importações. Assim, uma estratégia adequada de desenvolvimento deveria procurar aumentar a participação dessa classe de produtos em nossas vendas externas e reduzir sua participação nas compras do exterior, para possibilitar o relaxamento da restrição oriunda do balanço de pagamentos e estimular a produção nos setores que geram maior produtividade, mais externalidades positivas e encadeamentos produtivos.

Porém, os dados demonstram que as exportações brasileiras estão mais concentradas em produtos intensivos em recursos naturais, cuja elasticidade-renda da demanda por exportações é, em geral, relativamente mais baixa, enquanto nossas importações estão mais 
concentradas em produtos intensivos em tecnologia e conhecimento, cuja elasticidade-renda da demanda é razoavelmente elevada (sempre superior a um). O cenário observado é o oposto daquele apregoado pelos modelos teóricos analisados e que estimularia as taxas de crescimento da economia brasileira.

Por fim, recomenda-se que, como o Brasil possui vantagens comparativas relevantes na produção de produtos primários, é importante que as políticas públicas, notadamente a política macroeconômica e as políticas comerciais, industriais e educacionais possibilitem a retomada das exportações, a desconcentração das importações e a elevação dos investimentos nos setores da manufatura intensivos em conhecimento e tecnologia (nos quais - Brasil não possui tais vantagens), de forma a levá-los a contribuir para o processo de catching up da economia brasileira.

Cabe destacar, em especial, a importância da política industrial para promover o desenvolvimento desses setores fundamentais ao desenvolvimento econômico, de forma a aumentar a competitividade industrial e impulsionar inclusive a utilização dos recursos naturais, o que já vem sendo defendido por autores como Suzigan (1975) e Kupfer (2003).

\section{Referências}

Araujo, RA.; Lima, G.T. (2007). "A structural economic dynamics approach to balance-ofpayments-constrained growth". Cambridge burnal of Economics, 31(5), p. 755-774.

Barbosa-Filho, N. (2001). "The balance-of-payments constraint: from balanced trade to sustainable Debt”. Banca Nazionale del Lavoro Quarterly Review, n. 219, Dec.

Bresser-pereira, LC. (2008). “The Dutch disease and its neutralization: a Rcardian approach”.

Revista de Economia Política, 28(1), p. 47-71.

Bresser-pereira, LC, Oreiro, J.L;Marconi, N. (2014). "A theoretical framework for new developmentalism”. In: L Bresser-Pereira, $\rfloor$ Kregel eL Burlamaqui (Orgs.). Financial stability and growth:perspectives on financial regulation and new developmentalism. Abingdon: Poutledge, 2014. p. 55-73.

Chenery, H.; Sherman, R; Moshe, S (1986). Industrialization and growth. Oxford University Press, published for the World Bank.

Amoli, M.; Porcile, G.; Rovira, S (2010). "Structural change and the BOP-constraint: why did Latin America fail to converge?' Cambridge Journal of Economics. 34(2), p. 389-411.

Corden, W.M.; Neary $\rfloor$ P. (1982). "Booming sector and de-industrialisation in a small open economy”. Economic burnal, 92(368), 1982.

Cornwall, $\rfloor$ (1977).Modern capitalism: its growth and transformation. London: Martin Robertson.

Ferrari, M.; Freitas, F.; Barbosa, N. (2013). "A taxa de câmbio real e a restrição externa: uma proposta de releitura com elasticidades endógenas". Revista de Economia Política, 33(1).

Furtado, C (1961). Desenvolvimento e Subdesenvolvimento. Ro de Janeiro, Editora Fundo de Oultura.

Furtado, C. (2000). "Bementos de uma teoria do subdesenvolvimento".In: BIESOHOWSKY, R (Org.). Anquenta anos de pensamento na Cepal. Ro de Janeiro: Record, v. 1. 
Gouvea, R; Lima, GT. (2010)."Structural change, balance of payments constraint and economic growth: evidence from the Multi-Sectoral Thirlwall's Law". Journal of Post Keynesian Economics, 33(1), p. 169-204.

Hausmann, R; Hwang, J; Podrik, D. (2006). "What you export matters". Working papers, Center for International Development at Harvard University.

Hirschman, A. (1958). The strategy of economic development. New Haven, TC. Yale University Press.

Kaldor, N. (1978[1966]). "Causes of the slow rate of economic growth in the United Kingdom". In: N. Kaldor (Ed.), Further Essays on Economic Theory, Holmes \& Meier, N. York, pp. 282-310.

Kaldor, N. (1989). "Causes of the slow rate of economic growth in the United Kngdom". In: F. Targetti e A. Thirlwall(Eds.). The essential Kaldor. New York: Holmes \& Meier Publishers.

Kupfer, D. (2003). “Política industrial.” Econômica, Ro de Janeiro, 5(2), p. 281-298.

Lewis, A.W. (1958[1954]). "Economic development with unlimited supply of labor". In: Agarwala, Sngh (Eds.), The Economics of Underdevelopment. New York, Oxford University Press.

Lewis, A. (1958). "Economic development with unlimited supply of labor". In AGARWALA,SINGH. (Orgs.). The economics of underdevelopment. New York: Oxford University Press, 1958.

Marconi, N.; Magacho, G.; Pocha, I. (2014). "Estrutura produtiva e a dinâmica econômica nos BRICs: uma análise Insumo-Produto”. Economia Ensaios, 29, p. 119-134.

McCombie, J; Thirlwall, A. (1994). Economic growth and the balance of payments constraint. New York, S. Martin's Press.

McCombie, J.; Thirlwall, A. (1997). "Economic growth and balance-of-payments constraint revisited". In: P. Arestis,G Palma e M. Sawyer (Eds.). Markets, unemployment and economic policy. v. II, London: Poutledge.

Missio, F.; Jayme. JR F. (2011)."Structural heterogeneity, and endogeneity of elasticites on the balanœe-of-payments constrained growth model", Textos para Discussão CedeplarUPMG, 425, Cedeplar, Universidade Federal de Minas Gerais.

Moreno-Brid, $\mathrm{J}(2003)$. "Capital flows, interest payments and the balance-of-payments constrained growth model: a theoretical and an empirical analysis", Metroeconomica, 54(2).

Nassif, A; Feijó, C; Araújo, E (2015). "Structural Change and Economic Development: is Brazil Catching-up or Falling-Behind?' Cambridge burnal of Economics,39 (5),p. 1307-1332.

Nassif, A; Feijo, C; Araujo, E (2012). "Sructural change and economic development: is Brazil catching up or falling behind". Anais do $40^{\circ}$ Encontro Nacional de Economia, Porto de Galinhas, Dec.

Oreiro, J; Feijó, C (2010)."Desindustrialização: conceituação, causas, efeitos e o caso brasileiro". Revista de Economia Política, 30(2), 2010.

Palma, G. (2005). "Four sources of 'de-industrialization' and a new concept of Dutch Disease". In: 」 Ocampo (Org.). Beyond reforms: structural dynamics and macroeconomic vulnerability, Sanford: Stanford University Press and World Bank, 2005. p. 71-116. 
Pasinetti, L (1981). Sructural change and economic growth - a theoretical essay on the dynamics of the wealth of the nations, Cambridge: Cambridge University Press.

Prebisch, R (2000[1949]). “O desenvolvimento econômico da América Latina e seus principais problemas" In: R Bielschowsk, (org). Onquenta anos de pensamento na CPAL, Ed. Record, vol.1, p. 69-136.

Posenstein-Podan, P. (1943). "Problems of industrialization in Eastern Europe and SouthEastern Europe". Economic burnal,53.

Razmi, A.; Blecker, R (2006). "Developing country exports of manufactures: moving up the ladder to escape the fallacy of composition?" Working Paper 2005-02, revised version. Department of Economics, University of Massachusetts Amherst.

Rostow, W. (1956). "The take-off into self-sustained growth". The Economic Jurnal, 66(261), p. 25-48.

Suzigan, W. (1975). "Industrialização e política econômica: uma interpretação histórica". Pesquisa e Planejamento Econômico, Ro de Janeiro, 5(2), p. 433-474.

Thirlwall, A. (1979). "The balance of payments constraint as an explanation of international growth rates differences", Banca Nazionale del Lavoro Quarterly Review, v. 128, 1979.

Thirlwall, A. (1997). "Reflections on the concept of balance-of-payments-constrained growth". Jurnal of Post Keynesian Eoonomics, 19(3), p. 377-384.

Thirlwall, A; Hussain, M. (1982)."The balance of payments constraint, capital flows and growth rates differences between developing countries". Oxford Economic Papers, v. 34.

Thirlwall, A. (2006). "Growth and development with special reference to developing economies”. 8. ed. Palgrave Macmillan: Hampshire and New York, 2006. 